\title{
HUMANIDAD DIGITAL Y CONSTITUCIÓN DE SÍ: HACIA UNA NUEVA ADMINISTRACIÓN DE LOS DISPOSITIVOS DIGITALES
}

\author{
DIGITAL HUMANITY AND SELF-CONSTITUTION: TOWARDS A NEW \\ MANAGEMENT OF DIGITAL DEVICES
}

\author{
JUAN EMILIO ORTIZ \\ juane_ortiz@hotmail.com \\ Universidad Nacional de Rosario (Argentina)
}

\begin{abstract}
RECIBIDO: $27 / 05 / 2019$
ACEPTADO: 18/07/2019
\end{abstract}

Resumen: El presente trabajo se propone arrojar luz sobre la problemática relación entre los medios digitales y las formas de poder del capitalismo actual. Siguiendo esta línea, el eje central radicará en realizar una adecuada descripción del entramado constituido por la lógica algorítmica, la ontología, y la constitución de la subjetividad. A través de este método, me propongo realizar un abordaje materialista de la cuestión con dos objetivos específicos: Por un lado, exceder cierto idealismo que aún anida en la posición crítica y juzga a los medios digitales desde una añoranza nostálgica hacia un pasado supuestamente mejor; por otro, delinear una praxis filosófica capaz de señalar el lugar preciso que le caben a los medios digitales ante el avance de la dinámica de dominación del capitalismo imperante.

Palabras claves: Dispositivos digitales, capitalismo, neoliberalismo, Subjetividad, Praxis Filosófica, Materialismo.

\begin{abstract}
The present work aims to shed light on the problematic relationship between digital media and the forms of power of current capitalism. Following this line, the central axis will be to make an adequate description of the framework constituted by algorithmic logic, ontology, and the constitution of subjectivity. Through this method, I intend to make a materialist approach to the issue with two specific objectives: On the one hand, to exceed certain idealism that still nests in the critical position and judges the digital media from a nostalgic longing towards a supposedly better past; on the other hand, to delineate a philosophical praxis capable of pointing out the precise place that digital media can accommodate before the dynamics of domination of the prevailing capitalism.
\end{abstract}

Keywords: Digital Media, Capitalism, Neoliberalism, Subjectivity, Philosophical Praxis, Materialism.

\section{Presentación del problema: Las ventajas y desventajas de una humanidad digital}

En los últimos 30 años el avance de las tecnologías informáticas ha sido abrumador y ha modificado radicalmente las formas tradicionales de pensar la subjetividad, la sociedad y la política. Desde las publicaciones de los políticos en Facebook o Twitter, pasando por las sesiones de psicoterapia por Skype, y hasta 
el cultivo de relaciones múltiples por WhatsApp, la informática ha revolucionado aspectos fundamentales de la vida humana. Estas innovaciones han facilitado la comunicación y nuestro disfrute de determinadas formas de entretenimiento. También han generando una nueva modalidad de vínculos amistosos, laborales, profesionales y amorosos. Así, las redes sociales y los Smartphone se han convertido en partes indispensables de nuestras vidas. Consumimos una cantidad considerable de nuestro tiempo produciendo o siguiendo publicaciones hechas en Facebook o Twitter, una actividad que comienza a sustituir la lectura tradicional del diario o del noticiero para enterarse de temas actuales. Dependemos para nuestros viajes de la tecnología aportada por Google maps que diseña la ruta de acceso más conveniente para llegar a nuestro destino. Es indiscutible que el acceso aInnternet permite establecer vínculos más allá de los límites impuestos por las distancias y también la circulación de grandes caudales de información a la que accedemos desde nuestra propia casa o teléfono personal. El uso de la tecnología informática despierta nuevas esperanzas incluso en el terreno de la economía. En este campo ha surgido la expectativa de que el medio digital pueda canalizar y descomprimir el ritmo vertiginoso del sistema financiero drenando burbujas de capitales no invertidos. Muchos sostienen que el uso de Internet puede revertir la previsible crisis en las condiciones de trabajo. La tecnología digital podría generar una nueva dinámica para la oferta y la demanda de ciertos productos y servicios profesionales que encontrarían en la red mercados de consumo específicos en los cuáles insertarse. ${ }^{1}$

$\mathrm{Si}$, por ejemplo, alguien vive en una ciudad chica, probablemente no encuentre muchas personas a las que ofrecer clases particulares de temas puntuales de filosofía. Pero si crea una página de Internet e interactúa a través plataformas publicitarias (como Facebook, o Google) en las que ofrece su servicio docente, es posible generar que gente de cualquier parte del mundo lo contrate para esa función. Así, la red permitiría potenciar la singularidad en la oferta y la demanda de esa prestación. Plataformas como Uber o Airbnb están aplicando una lógica similar y generan sus ingresos ofreciendo servicios con costos mínimos de inversión que canalizan las demandas de un espectro diverso y amplio de consumidores. Todo se desarrolla bajo la premisa de atraer trabajadores - socios motivados por condiciones flexibles de contratación y por

\footnotetext{
${ }^{1}$ Así lo describe una nota del diario Página 12: "Los defensores del actual orden dominante aducen que la economía digital generará trabajos altamente adiestrados y bien pagados y que resolverá los problemas de la polarización social y el estancamiento. Pero todo indica lo contrario: la economía digital acelerará la tendencia hacia un cada vez mayor desempleo y subempleo junto con una mayor ampliación del empleo precario y casual. Estamos a punto de ver la aniquilación digital de mayores sectores de la economía global.” (https://www.pagina12.com.ar/94926-burbujas).
} 
una mayor libertad de acción. ${ }^{2}$ En efecto, este es el argumento central de la publicidad que circula actualmente en los medios televisivos de un taxista Uber en la cual se resalta el lema "Socio, conductor y estudiante". ${ }^{3}$ La misma acentúa que asociarse a la plataforma, puede ofrecer la posibilidad de un ingreso y una carga horaria regulada a gusto del trabajador, una posibilidad que le permitiría desarrollar con comodidad su propio proyecto de vida.

De acuerdo con los estudios de Marshall Mcluhan sobre las leyes de medios, sabemos que un artefacto se presenta como una extensión de alguna capacidad del ser humano generando el reemplazo de otros medios que se vuelven obsoletos. ${ }^{4}$ Siguiendo esta lógica, no tiene demasiado sentido pensar en una vuelta atrás con respecto a la expansión de estos medios digitales. La singularidad de estos artefactos es que, a diferencia de otras herramientas mecánicas (como un martillo), generan una especie de extensión de tipo "espiritual". En efecto, actúan reproduciendo en el medio digital un conjunto amplio de gustos, intereses, deseos, es decir, todo aquello que configura una identidad, una imagen, una historia personal. Lo que emerge a través de la tecnología digital es una subjetividad hibridada a sistemas algorítmicos a los cuales se les delega de modo creciente el control de información, la toma de decisiones, el refuerzo permanente de nuestras creencias y costumbres. ${ }^{5}$ En suma, el artefacto digital está configurando una verdadera antrobología (Sadin,

\footnotetext{
${ }^{2}$ La dinámica del Capitalismo de plataformas es estudiada en detalle en el reciente libro del economista canadiense Nick Srnicek: "Las plataformas, en resumidas cuentas, son un nuevo tipo de empresa; se caracterizan por proporcionar la infraestructura para intermediar entre diferentes grupos usuarios, por desplegar tendencias monopólicas impulsadas por efectos de red, por hacer uso de subvenciones cruzadas para captar diferentes grupos de usuarios y por tener una arquitectura central establecida que controla las posibilidades de interacción". (Srnicek, 2018: 49).

${ }^{3}$ El spot publicitario puede verse en: https://www.youtube.com/watch?v=FQqqPDn5Jok.

4 "Las cuatro leyes se formulan como cuatro preguntas: - ¿Qué es lo que el medio extiende, intensifica, acelera o hace posible? Esta cuestión puede plantearse para una papelera, una pintura, una máquina de vapor o una cremallera, lo mismo que a una proposición euclidiana o a una ley de la Física. Puede plantearse en cualquier mundo o mediante cualquier lenguaje. - Cuando el medio extiende o potencia un aspecto, simultáneamente se atrofia o desaparece un aspecto de la anterior situación o condición. ¿Qué reduce o hace obsoleto el nuevo "órgano"? - ¿Qué acciones, servicios o formas de medios retornan o son recuperadas con el surgimiento del nuevo medio? ¿Qué bases anteriormente obsoletas o anticuadas son recuperadas e integradas por la nueva forma mediática? Cuando la nueva forma de medio es llevada hasta su límite en sus potencialidades, (fenómeno que también es complementario) tiende a producir una reversión y un retorno a la situación previa a su aparición. ¿Cuál es la reversión potencial de la nueva forma mediática?’(Mcluhan, M; Mcluhan, E., 2009: 290).

5 "Se trata de una humanidad ya no sólo interconectada, hipermóvil, que hace del acceso un valor capital, sino que, de ahora en adelante, está hibridada con sistemas que orientan y deciden comportamientos colectivos e individuales, bajo modalidades todavía discretas pero ya pregnantes, y que están destinadas a extenderse hacia numerosos campos de la sociedad" (Sadin, 2018: 60).
} 
2018: 84), es decir, un hibrido entre la subjetividad y una lógica algorítmica que asiste a la inteligencia humana en aspectos cada vez más amplios de nuestra vida cotidiana.

Ahora bien, en este contexto es preciso advertir que la tecnología digital no es neutral. Sería ingenuo pensar que Internet es una herramienta de dominio público o una especie de patrimonio de la humanidad creado con vistas al bien común. Una gran cantidad de autores ya ha estudiado con intensidad de qué modo las supuestas ventajas que ofrece la tecnología digital se anudan con intereses empresariales y políticos bien concentrados. El reciente libro de Eric Sadin (2018 b) expresa esta cuestión con el título provocador de Silicolonización. A través del mismo denuncia la expansión conquistadora de un ethos surgido en Silicon Valley. El mismo constituye una cosmovisión singular pero que ostenta aspiraciones universales. Otro estudio interesante es el de José Van Dijck (2016), quien analiza en detalle de qué manera las redes han naturalizado el imperativo del "Compartir" y el "Seguir", que se insertan en una lógica de competencia, de establecimiento de jerarquías y conexiones que es propia del neoliberalismo. Todo eso se combina con el botón de "Me gusta" creado por Facebook que sirve para trazar complejas estrategias de venta, que incluye productos, viajes, vacaciones, etc. En esta línea, Byung Chul Han sostiene que la tecnología digital favorece lo que él llama Piscopolítica (2014), que se presentaría como una nueva forma de dominación en la que los mecanismos de poder se han interiorizado. El sujeto actúa explotándose a sí mismo al tiempo que cree estar realizándose. Lo que en apariencia es comunicación, apertura al otro, generación de nuevos recursos, no es más que un encierro en un narcisismo acentuado por la dinámica digital. Más importante aún es el juicio de Nick Srnicek sobre las supuestas bondades de la economía digital (como la que ofrece Uber) que no deja de ser una "continuación del neoliberalismo por otros medios" (Srnicek, 2018: 122). Además, la acumulación de capital por parte de las empresas informáticas, se canaliza hacia cuentas offshore que generan un desfinanciamiento de los Estados a través de la evasión fiscal (Srnicek, 2018: 35). Por lo tanto, esta economía digital termina influyendo en la situación económica de los Estados que son los únicos que pueden hacer regir un marco normativo para regular las concentraciones de poder (político, cultural, comunicativo) que, de modo creciente, acaparan la actividad de las empresas informáticas.

Por todas estas razones, el vínculo entre los medios digitales y las dinámicas de poder neoliberal es un tema que merece gran atención. En esta línea, si bien la bibliografía citada describe con precisión el síntoma en el cual estamos inmersos por la acción de estas tecnologías, existe alguna confusión para definir claramente una propuesta ética, política y filosófica que permita posicionarse de 
un modo crítico y a la vez activo ante el avance de los medios informáticos. El problema no es sencillo. No obstante, entiendo que puede arrojarse luz sobre el mismo a partir de una adecuada descripción del entramado constituido por la lógica algorítmica, la ontología, y la constitución de la subjetividad. Por estas razones, en el presente escrito intentaré hacer uso de un método materialista que busca percibir lo real de la situación y que apunta a dos objetivos específicos: ${ }^{6}$ Por un lado, exceder cierto facilismo que anida en la posición crítica y juzga a los medios digitales desde una añoranza hacia un pasado supuestamente mejor; por otro, delinear una praxis filosófica capaz de señalar el lugar preciso que le caben a los medios digitales para evitar ser consumidos por la dinámica de dominación del capitalismo imperante.

\section{Algoritmos, lógica y ontología}

Un estudio de la historia de la tecnología informática reviste el valor de todo planteo genealógico. Permite apreciar los orígenes contingentes, relacionales, y políticos de aquellos discursos con pretensiones de verdad. Al mismo tiempo, ofrece una mirada del proceso a través del cual esos discursos se anudan a una creencia en el Ser de las cosas, es decir, conforman una ontología. Esta es la impresión que genera la lectura del libro de Pablo Rodríguez titulado Historia de la Información (2012). Allí el autor analiza el recorrido histórico de una cuestión que hoy se concibe casi como una verdad indiscutible: Todo es información; En efecto, algunos discursos postulan que el universo mismo, nuestras funciones biológicas, las cadenas de ADN y la actividad de nuestro cerebro, funcionarían con una lógica de tipo computacional: "La computadora deja de ser el cerebro artificial imaginado por Von Neumann, para transformarse en una 'máquina del alma', y en ese mismo movimiento de complejización también pasa a ser el modelo epistemológico de comprensión de la vida.” (Rodríguez, 2012: 61)

\footnotetext{
${ }^{6}$ En el desarrollo del trabajo se irá exponiendo lo que entiendo por método materialista conjuntamente con la descripción del problema en cuestión. Al hablar de materialismo, por supuesto que me remito a la filosofía de Marx como fundadora de un modo de interpelar la realidad que pone en evidencia el fetichismo de las instituciones. Es decir, el conjunto de relaciones diferenciales que subyacen a toda la dinámica social. A su vez, también reconozco la influencia de Althusser que apuesta a percibir el carácter ideológico que anida en el lenguaje mismo y en las diversas formas de conocimiento. Por otro lado, el planteo está atravesado por la filosofía de Badiou con su dialéctica materialista y algunas herramientas extraídas del último Foucault y su reflexión sobre el proceso de subjetivación. En suma, por método materialista entiendo un modo de interpelar la realidad que considera la sobredeterminación compleja de factores políticos, ideológicos, económicos, subjetivos y que se anudan de un modo singular en cada situación concreta.
} 
Es interesante considerar que el autor sitúa el origen de la racionalidad computacional en los desarrollos de la estadística en el siglo XVIII y en una identificación de la lógica y la matemática que proponía el filósofo alemán Gottfried Leibniz (Rodríguez, 2012: 23). Él pensaba que el hecho de que ambas disciplinas utilizan un lenguaje formalizado habilitaba que recibieran el mismo tratamiento. Así, Rodríguez afirma: "Son muy complejos los argumentos que se esgrimieron en la querella (entre formalistas y no formalistas) y su resultado es incierto, pero del impulso formalista unido a ciertas investigaciones tecnológicas surgió en pocos años la computadora, tal como hoy se la conoce." (Rodríguez, 2012: 24). Al seguir el libro de Rodríguez se puede apreciar con detalle las sucesivas transformaciones que la ciencia de la computación experimenta hasta convertirse en un poderoso paradigma explicativo de la realidad social, física, biológica, etc. Pero lo que me interesa resaltar a partir de su propuesta es la historicidad de los desarrollos informáticos.

Siguiendo esta línea, me pregunto aquí si este paradigma que anima nuestra tecnología digital, no conserva aún el principio teleológico que puede percibirse en algunos desarrollos de nuestra tradición filosófica. Es sabido que, para Leibniz por ejemplo, existe una primacía ontológica del Ser sobre el No Ser pero, detrás de la misma, opera un presupuesto lógico y valorativo que no se cuestiona: El mundo actual es una elección Divina y ha sido creado eligiendo entre el mejor de los mundos posibles. El genio de Leibniz le permitió reconocer la posibilidad de infinitos mundos lógico - matemáticos. Le permitió asimismo advertir la importancia de las singularidades irreductibles en la constitución de estos mundos. Sin embargo, él subsumió estas intuiciones a un principio de necesidad con una dirección valorativa bien precisa. Aquello que sea la ley de lo mejor constituye un asunto sumamente discutible, pero actúa dándole un sentido $a$ priori a una realidad que resulta, en principio, indeterminada. Siguiendo estas ideas, gran parte de nuestra tradición filosófica reducirá el problema de la verdad a un supuesto lógico y valorativo que aspira a regular la aparición del acontecimiento como tal. De este modo, surgen todo tipo de discursos sobre el ser de las cosas como una existencia necesaria con una finalidad específica que se impone. La problemática del sujeto no es inmune a esta dinámica de unificación que subordina la multiplicidad de factores intervinientes en la vida del animal humano a una identidad definitiva e inamovible.

En relación a esto último, es interesante considerar una apreciación de Bruno Latour. El sociólogo francés advierte el peso de este tipo de teorías de raíz teleológica y teológica en el terreno de la economía y la sociología. Tanto el liberalismo como el socialismo parten de un supuesto ontoepistemológico común 
que se refiere a la organicidad de lo social. ${ }^{7}$ El mismo remite al presupuesto de que la sociedad funciona como una unidad, como un cuerpo, con vistas a un fin específico determinado de manera necesaria. Creo que es posible aplicar este gesto sugerido por el sociólogo francés a la racionalidad algorítmica. Constituye una tarea interesante rastrear su carácter inventivo y la potencia que de allí se deriva: Por un lado, advertir la contingencia de esa racionalidad, es decir, tomar consciencia de la singularidad de su Ser-de-tal-modo, sin perder de vista su nonecesidad; Por otro lado, pensar puntos de transformación para la misma: Por un lado, advertir su contingencia, es decir, tomar consciencia de la singularidad de su Ser-de-tal-modo, sin perder de vista su no-necesidad; Por otro lado, permite pensar puntos de transformación para los mismos. Esta senda conduce inevitablemente a interrogarse por el carácter de esa invención, ¿cuál es la red compleja de deseos, creencias e intereses que motivan la misma? ¿Cuáles son sus consecuencias? ¿Qué transformaciones producen las tecnologías digitales en esta amplia red de los asuntos humanos?

Presuponer un sentido a priori que unifique la multiplicidad del acontecimiento conduce a restar importancia al carácter de decisión e invención que resulta inseparable de cualquier planteo ontológico. En este sentido, creo que es preciso seguir una intuición de Badiou cuando sostiene que la característica de la filosofía desde Leibniz (pero también desde Aristóteles) es precisamente identificar la matemática con la lógica. Desde este punto de vista sería preciso separarlas, ya que: "Ningún cálculo exterior a la decisión es capaz de proponer una ley de lo mejor" (Badiou, 2002: 116). Así, para el pensador francés, la matemática constituye una ontología desde el momento en que decide un mundo e introduce una axiomatización en la multiplicidad indiscernible de las cosas. ${ }^{8} \mathrm{~A}$ partir de allí es viable reflexionar acerca del aparecer lógico de ese múltiple. Pero no existen razones suficientes para pensar que la lógica está unida al ser mismo

\footnotetext{
${ }^{7}$ En este sentido, Latour y Lépinay afirman: "De los dos lados de la gigantomaquia que opone el dirigismo y el dejar-hacer, el socialismo y el neo-liberalismo, tienen los mismos principios de sociología - la idea "de organismo"-, los mismos principios de economía - la "predestinación providencial"-, los mismos principios de moral - "la creencia en la armonización espontánea de las sociedades". ¿Pero cómo hacerlo de otro modo? ¿Cómo escaparse a este "seductor error"?"(Latour; Lépinay, 2007: 147).

${ }^{8}$ En relación a este punto, Badiou señala: "la ontología no puede reducirse a la lógica de la ontológica. La matemática real no es una inspección matematizada de los universos matemáticos posibles. La matemática real decide un universo. Por consiguiente, la relación entre la lógica y la matemática es la que existe entre una investigación general de los recursos lógicos de una ontología y una decisión ontológica que conlleve sus propias consecuencias lógicas. Esto quiere decir también que la lógica es definicional, mientras que la matemática es axiomática. De este modo, si uno decide axiomáticamente que el pensamiento del ser se realiza en el marco de la teoría de conjuntos, habrá asumido que su lógica es clásica." (Badiou, 2002: 116).
} 
de las cosas y determina su sentido. Trazar esta distinción es una clave para frenar los efectos de la tendencia idealista de la filosofía. Es preciso "mostrar también que hay una lógica de la verdad, pero que de ningún modo hay una verdad de la lógica" (Badiou, 2002: 118).

Creo que esta reflexión es muy importante para aplicar a la producción de algoritmos. La misma es lógica, pero no puede ser elevada a una estructura de aquello que sea la realidad en sí misma. Aquí se encuentra la primera torsión materialista propuesta por este escrito y que consiste en señalar los alcances y límites de la técnica. Esto constituye un giro que apunta a reconocer la distinción entre la multiplicidad del ser y su indexación lógica en mundos específicos. Desde este punto, no sería del todo prudente caracterizar determinados desarrollos de la tecnología informática como un contacto fiel con un flujo infinito de información, con una multiplicidad indiscernible o con el ser mismo de las cosas. Por el contrario, un dispositivo como Internet, con su creciente gobierno algorítmico sobre la vida humana, parece ser una producción que corresponde al saber normalizado. Es decir, se presenta integrando la lógica singular de nuestro mundo actual y se encuentra vinculado a una sedimentación histórica de determinadas identidades. A su vez, es subsidiario de medios materiales específicos y de quienes detentan el control de los mismos. Es muy significativa una opinión de Boris Groys cuando afirma que Internet es precisamente una limitación del infinito: "Muchas veces pensamos en Internet en términos de flujo infinito de información que trasciende el límite del control individual. Pero, de hecho, Internet no es el lugar del flujo de información, es una máquina que detiene e invierte ese flujo." (Groys, 2016: 203). Así, el problema se refiere a las posibilidades concretas que ofrece la tecnología digital para habilitar un reconocimiento de lo acontecimental, es decir, de lo radicalmente otro en el terreno del arte, de la política, del amor y en lo que atañe a la constitución de la subjetividad.

Este bloqueo del flujo es el principal peligro que advierte Sadin en su estudio sobre la expansión de un ethos neoliberal hibridado a la tecnología digital. El argumento muestra que la producción algorítmica, si bien parece prolífica, benevolente y sumamente inventiva, está encorsetada dentro de la ontología totalitaria del neoliberalismo. Esta producción se asienta en una voluntad de verdad sumamente dominante que pretende excluir toda diferencia y se concibe a sí misma como una verdad definitiva acerca del universo entero. Las tecnologías digitales no son neutrales. No hay neutralidad en la técnica. Por el contrario, son el efecto de exitosos intereses de mercado y generan un movimiento contrario al desarrollo de una ética entendida como trabajo sobre sí o como política virtuosa de nosotros mismos: "Las lógicas técnico económicas que hoy están mayormente 
vigentes son contrarias a la ética en la medida en que apuntan a un dominio total, pretendiendo someter todos los gestos a resultados de ecuaciones según un principio que constituye una ofensa a la integridad humana." (Sadin, 2018b:44). Según el autor, las principales empresas productoras de tecnología digital han estado orientadas por un ethos megalómano (Sadin, 2018b: 67). Sus principales ideólogos hacen gala de ideas patológicas que expresan el deseo de eliminar los límites, las fallas y los errores en el universo e intentan crear un mundo ideal de las cosas (Sadin, 2018b: 110). La aspiración máxima de este avasallamiento a la condición humana se encuentra en el transhumanismo que alienta la esperanza de generar medios técnicos que permitan trascender el umbral de la muerte. ${ }^{9}$ Así, el espíritu rector de Sillicon Valley se asienta en el presupuesto de que la naturaleza humana es defectuosa pero puede, con la ayuda de la tecnología digital, evolucionar y perfeccionarse hasta constituir un orden común de perfecta concordancia. Este principio de unificación y esta voluntad de verdad supuestamente superior constituye la principal amenaza a la que nos somete la tecnología digital, ya que apunta a la eliminación de lo político como tal y la promoción de una libertad individual a la altura de estos de comportamientos considerados como superiores:

La ontología tecnolibertaria consiste en descalificar la acción humana en beneficio de un 'ser computacional' que se juzga superior (...) Su filosofía política se vale de una a-política o una tecnopolítica que procura liberarse de lo político entendido como la libre capacidad de los individuos y de los pueblos para decidir, en común y dentro de la contradicción, su destino singular. (Sadin, 2018b: 126).

\section{La inteligencia artificial como cristalización de las relaciones de poder}

Lo dicho en el apartado anterior invita a reflexionar sobre los riesgos que aparecen cuando se pierde de vista la sobredeterminación entre valores, intereses económicos y principios rectores de una ontología. Este problema es bastante típico y es el resultado de la tendencia idealista señalada más arriba. Existen algunas creencias que se sedimentan conformando identidades y fundamentan

\footnotetext{
${ }^{9}$ La película Trascendence (2014) protagonizada por Johnny Deep y Morgan Freeman se presenta como una ficción interesante que encarna esta temática. Un científico de la computación es atacado a causa de sus ideas y está al borde de la muerte. Su mujer y su amigo hacen una copia de su mente a una computadora. La película resulta sintomática. Ya que surge de este modo un hibrido humanodigital que comienza a imponer su propio criterio adquiriendo cada vez mas dominio sobre distintos aspectos de la vida humana. (Trailer: https://www.youtube.com/watch?v=1gSUx07DFbI).
} 
formas de proceder institucional que se piensan como manifestaciones del ser mismo de las cosas.

Ahora bien, en el caso singular de la tecnología digital la situación llega a ser un tanto más compleja. Sobre todo porque la misma ha alcanzado una influencia sin precedentes en la vida cotidiana de las personas. Basta considerar la invención del Smartphone que es un aparato que permite una conexión ininterrumpida con el flujo digital. El nudo principal de este entramado de relaciones se despliega ante las características de lo que se conoce como Inteligencia artificial. Los robots digitales constituyen un tipo de entidad electrónica con diferencias especificas en relación a la inteligencia humana, que están definidas por su incorporeidad, su velocidad extrema y su potencia cognitiva. (Sadin, 2018: 111). Si bien los mismos no son totalmente autónomos, poseen una estructura de algoritmos que les permite manipular grandes cantidades de datos, ejecutar ciertos razonamientos e ir modificando sus conocimientos acerca del entorno con el que interactúan. Este tipo de programas se ha vuelto moneda corriente en muchas experiencias de nuestra vida cotidiana. ${ }^{10}$

Más allá de cierto grado de utilidad parcial que podríamos reconocerle a esta tecnología, la robotización digital tiene la potencialidad de generar que nuestras acciones se inserten en una lógica de mercado. Es decir, automatiza el uso capitalista de nuestros gestos más cotidianos. A su vez, la dependencia creciente hacia estos artefactos tiende a acentuar de modo a-crítico la propia singularidad. ${ }^{11}$ No se trata sólo de que el proceso promueva la homogenización y la imposición de gustos específicos, sino de la complejidad que introduce en la dinámica de las relaciones de poder. Ya que apunta directamente a la relación de

\footnotetext{
${ }^{10}$ Por ejemplo, están operando cuando realizamos una búsqueda en Google sobre algún tema de nuestro interés y luego, abrimos Facebook, y recibimos publicidades, ofertas, sugerencias en relación a dicha búsqueda. Otras plataformas como Netflix o Youtube utilizan estos programas para sugerirnos películas o música que puede interesarnos en relación a nuestro consumo previo. La interacción se produce entre el usuario que otorga datos acerca de algún producto específico y un programa que le otorga a otra plataforma información sobre esa búsqueda. Las entidades digitales interactúan así con el usuario y con otros robots digitales.

${ }^{11}$ Es interesante una opinión de Sadin cuando sugiere que la dinámica de poder que impone la tecnología digital ya no se basa tanto relaciones de influencias de una persona sobre otra, Sadin menciona en varios lugares que la característica de los sistemas de inteligencia artificial es generar un refuerzo de la propia singularidad: "Los procesos deductivos contemporáneos no buscan 'borrar las diferencias' ni 'uniformizar los regímenes', sino que, por el contrario, están adiestrados para exaltar al máximo cada circunstancia singular. No se proponen inscribir y reducir los seres y las cosas a esquemas idénticos y homogeneizantes, sino ajustar el conjunto de fuerzas susceptibles de encontrarse entre sí dentro de todo fragmento espacio-temporal considerado oportuno" (Sadin, 2018: 139).
} 
si pero asistida por una lógica computacional imperceptible. Pensemos por ejemplo en los algoritmos que nos sugieren música o películas de acuerdo a nuestra elección previa. Es muy cómodo conectarse a Youtube y disfrutar un buen rato de música de nuestra preferencia. A través de Internet uno puede recuperar música de autores y géneros que de otro modo estarían perdidos para siempre. Sin embargo, este ejemplo que muestra la potencia del medio informático, revela también un límite. En efecto, ¿puede la tecnología por sí misma ponernos en contacto con expresiones artísticas variadas? ¿o nos arriesga a caer en la repetición de lo mismo, una repetición que suele ir en la línea de las tendencias más dominantes en el mercado? Este hecho se hace invisible ya que no se encarna en ninguna entidad específica y uno tiene la ilusión de estar siguiendo su propio arbitrio.

Así, el problema principal radica en la dependencia creciente e inconsciente respecto de este tipo de entidades digitales. Esta subordinación llega a constituir una neo gubernamentalidad en la cual nuestra vida resulta asistida por la tecnología digital. En este sentido, el uso del algoritmo inteligente termina condicionando efectivamente nuestras decisiones, organizando nuestros espacios, promoviendo formas de disfrute, excluyendo otras y regulando nuestros encuentros corporales. Por esta razón, creo que el punto de intersección entre la inteligencia humana asistida por la inteligencia artificial puede producir un refuerzo de determinadas lógicas de poder. Aventurarse a un uso improvisado de la técnica que no considere sus implicancias éticas y políticas tiene riesgos que es preciso analizar.

El peligro más grave radica en el traspaso de valores, creencias, criterios estéticos a la producción algorítmica generando el refuerzo permanente de identidades, formas de consumo y hasta de decisiones jurídicas y/o políticas. Podrían citarse un sinnúmero de ejemplos interesantes para abonar estas hipótesis. Sadin se refiere al proyecto google car, que tiene como objetivo una guía robotizada de nuestros viajes. El contenido manifiesto del dispositivo se refiere a la posibilidad de minimizar accidentes a través del cálculo algorítmico de las variables de tránsito. No obstante, como contrapartida de la posibilidad de viajar sin tener que manejar, aparecerían sugerencias de visitas a centros comerciales o productos a través de videos pagos (Sadin, 2018b: 133). También están aquellos programas que delegarían la decisión de compra de nuestros artefactos a través de un monitoreo de su deterioro y su encargo automatizado a una tienda online. (Sadin, 2018b: 148).

Más preocupante aún es la confianza en programas que están decidiendo quien está apto para recibir un crédito y quien no lo está. Hay otros programas que tienen la función de asesorar a magistrados o abogados ante ciertos casos y 
se están utilizando como apoyo para decidir el contenido de sentencias. Tal es el caso del software Compas de la empresa Northpointe. El mismo fue utilizado recientemente por una corte del Estado de Wisconsin en EEUU para decidir el encarcelamiento de Eric Loomis quien, según el software consultado, tenía grandes probabilidades de reincidir en conductas delictivas. Esta persona resultó condenada a prisión porque un programa informático -cuyo algoritmo se desconoce- emitió su "opinión" acerca de lo que podía ser su comportamiento futuro. Es evidente que el software actúa con algunos presupuestos de base que no resultan cuestionados, por ejemplo: el encarcelamiento como única forma de intervenir para la resolución de conflictos que son efecto de problemas sociales más complejos. Existen también prejuicios más graves que se filtran en el programa y que derivan en un sesgo algorítmico alarmante:

COMPAS, además, refleja los sesgos de sus creadores. Como explica el abogado de Cremades \& Calvo-Sotelo Diego Solana, «posteriormente, a través de técnicas de ingeniería inversa, otro estudio demostró que COMPAS daba una mayor puntuación y, por tanto, mayor posibilidad de reincidencia a las personas de raza negra que a las de razablanca (https://www.elmundo.es/papel/futuro/2018/09/04/5b883125e5fdea97248b45d6.h tml).

En relación a los efectos que la tecnología digital tiene sobre el dispositivo de la justicia, resulta muy interesante el análisis realizado por Zaffaroni y Dos Santos en un reciente libro titulado La nueva criminología crítica. El actual capitalismo de plataformas actúa promoviendo la creación de identidades digitales. Estos datos definen perfiles de consumidores y son vendidos a grandes empresas para diseñar estrategias de venta. En el mismo movimiento, la creación de este doble digital, puede contribuir a arrojar información sobre personas cuyos perfiles pueden ser considerados "peligrosos": "Lo cierto es que, cuando el marketing configura con datos ingenuos un doble informático del consumidor, también lo está haciendo del peligroso y del votante." (Zaffaroni; Dos Santos, 2019: 158159). ${ }^{12}$ Así, el uso del medio, no lograría prevenir contra el prejuicio ni la estigmatización arbitraria. Tampoco promovería la comprensión de las profundas

\footnotetext{
${ }^{12}$ Un poco más abajo, los autores agregan: "Seguridad, telecomunicaciones, correos, hospitales, previsión social, tránsito, servicio públicos, aduanas, tarjetas de crédito, suscripciones de publicaciones, etc., dan lugar a ficheros y son objeto de compra y venta para marketing, pero también lo pueden ser para vigilancia de seguridad y política, pues son útiles para establecer riesgos y poblaciones de riesgos, según lo que en cada caso se entienda por tales." (Zaffaroni; Dos Santos, 2019: 158-159).
} 
causas sociales, económicas y políticas que se anudan en el núcleo de determinadas conductas.

Lo dicho anteriormente son sólo algunos ejemplos para visualizar que la tecnología digital puede contribuir a reforzar lógicas de exclusión y posiciones de dominación. Creo que este efecto es consecuencia de esa dialéctica singular que encarnan los dispositivos entre la sedimentación de algunos discursos y la constitución de identidades. En esta línea, vale la pena realzar nuestro argumento. La producción de algoritmos no tiene nada que ver con un contacto con la estructura misma de la realidad. Por el contrario, es una invención deudora de un conjunto de intereses empresariales y que tiene su asiento en deseos, creencias, y necesidades de los individuos. Sólo a través del reconocimiento del modo en que están imbricadas estas tramas se puede llegar a dimensionar el lugar preciso que es deseable otorgarles a este tipo de medios.

\section{Un nuevo substancialismo de la subjetividad}

Uno de los temas más álgidos que produce el hibrido antropo-digital es la pérdida de una dimensión crítica para pensar la constitución de la propia subjetividad. Dicho en otros términos, genera el riesgo de perder cada vez más herramientas para habilitar y enriquecer una relación de sí que sea capaz de transformar las condiciones del capitalismo reinante. La tecnología digital representa una extensión de nuestro propio espíritu. Esa es su singularidad. Los datos que arrojamos a Internet -ya sea patrones de consumo, imágenes, reflexiones, opiniones políticas- constituyen una reproducción digital de nuestra identidad. Pero esta reproducción no es fiel. En rigor, ninguna identidad lo es, ya que no existe una substancia subjetiva como unidad esencial y exenta de antagonismo que pueda orientarnos en el arduo sendero de la constitución de nosotros mismos. El problema con la "identidad digital" es que está atravesada por las características de un medio, es decir, por una especie de trascendental que impone condiciones particulares. Nuevamente aquí podemos operar una torsión materialista al despegar este trascendental de la realidad tal como es. El mismo remite a la naturaleza del Sujeto del Administrador que sugiere Groys. Una especie de sujeto universal y anónimo encarnado en plataformas como Facebook o Google, que parecen no emitir un punto de vista sobre las cosas pero crean condiciones para que otras personas puedan satisfacer deseos y realizar proyectos. No obstante, como se ha dicho, la estructura de este medio cambia la naturaleza del mensaje singular contenido en él. Como señala Groys: "sabemos, gracias a Marshall McLuhan, que el medio socava, subvierte y altera cada 
mensaje individual que utiliza ese medio (...) Los flujos de información disuelven, tuercen, y subvierten todos los mensajes individuales convirtiéndolos en aglomeraciones más o menos accidentales, en significantes flotantes." (Groys, 2016: 185,186). Estas ideas permiten dimensionar en qué sentido los desarrollos técnicos son capaces de imponer sus propias reglas.

Este desdoblamiento permite apreciar que, poner en relación nuestra subjetividad con el medio digital, no supone reflejarse en un espejo perfecto. Por el contrario, el mismo nos devuelve una imagen de nosotros mismos contaminada por estos elementos de fondo que se vuelven imperceptibles. Aquí es donde la asistencia permanente de la inteligencia artificial hacia la relación de si entra en un proceso que es necesario advertir. La tecnología digital vuelve utópica aquella impronta relacional y deconstructiva que los pensadores posmodernos se esforzaron por avivar. Internet se presenta como una herramienta que archiva y registra hasta los gestos más mínimos, y todas aquellas imágenes, reflexiones personales y expresiones de deseo que uno emite quedan anudadas a una identidad nominal e individual. Desde este punto de vista, y haciendo abstracción de los medios materiales que necesita para subsistir, esta herramienta constituye una suerte de regreso a la metafísica, al punto de vista de un Gran Espectador. (Groys, 2016: 164,165). Por otro lado, a la luz de lo dicho, cabe preguntarse si esta reproducción digital de la propia vida no contribuye a consolidar la ilusión de la subjetividad como una individualidad substancial, como una unidad volitiva concentrada en sí misma de la cual está ausente el conflicto y la relación con el otro como alteridad.

A su vez, se sabe a partir de las ultimas ideas de Foucault que las relaciones de dominación se incardinan en el juego sobredeterminado de las técnicas de sí. Cada cultura está provista de una manera de abordar la relación consigo mismo, de constituirla y de desarrollar una espiritualidad conforme a parámetros culturales vigentes. En las tramas de esta cultura de sí se asienta la relación entre conductor y conducido. Por esta razón, para realizar un análisis de las formas de dominación, se deben tener en cuenta: "los puntos donde las tecnologías de dominación de unos individuos sobre otros apelan a los proceso por los cuáles el individuo actúa sobre sí mismo; y a la inversa, los puntos donde las técnicas de sí integran estructuras de coerción y dominación" (Foucault, 2016: 45).

Así, si se presta atención a sus últimos textos, se aprecia que el filósofo se interesa por la noción de cuidado de sí. Sólo a través de un efectivo cuidado resulta posible minimizar situaciones de dominación. Esto no supone que la subjetivación se despliegue necesariamente como un desafío rotundo con respecto a lo normalizado sino a partir de la constitución de una relación de sí que sea lo más autónoma y responsable posible. En otros términos, se trata de 
desarrollar una actitud que no presuponga en ningún momento una sumisión sin crítica ante una identidad de carácter substancial, ante una forma normalizada y trascendente de ser sujeto. En los textos estoicos Foucault encuentra experiencias de una praxis filosófica que entiende la relación de sí como una relación más entre las cosas del mundo, una relación sin jerarquía con respecto a ellas; fuertemente atravesada por una singularidad histórica y que no aparece ni totalmente determinada ni totalmente libre. De lo que se tratará es de poder elaborar esa relación de sí con un estilo singular e irreductible atravesado, de modo simultáneo, por un vínculo necesario con los otros, con las demás cosas, con los dispositivos técnicos, con los parámetros éticos de una cultura, etc. No se propone así una vuelta a la antigüedad, sino que se estudia la experiencia de vivir la relación de sí liberada del presupuesto de una identidad substancial ${ }^{13}$.

Considero que la deriva del planteo foucaulteano constituye también una torsión materialista. La misma muestra que no seremos capaces de lograr un posicionamiento activo ante las formas de dominación si no trabajamos en una política madura de nosotros mismos y de nuestra relación con los demás. El punto es que la tecnología digital torna cada vez más complejo este trabajo con el riesgo de volver imperceptible la sumisión ante una identidad de este tipo. En esta dinámica, hay formas de odio, rechazo hacia los otros y hacia sus formas singulares de goce, que puede ser potenciada a través de la naturalización generada por los medios digitales. ${ }^{14}$

\footnotetext{
${ }^{13}$ El recorrido que Foucault hace por la filosofía estoica apunta a señalar una especie de movimiento de des-fetichización de valores e identidades que demuestra la pequeñez y la contingencia de aquellos fines que persiguen los hombres. Resulta significativa la recuperación de este pasaje de Marco Aurelio que demuestran la imposibilidad de pensar una identidad como unidad fija y permanente. Para no caer en engaños y dominaciones será preciso descomponer las cosas evitando caer en el hechizo mediante el cual esas identidades ilusorias amenazan cautivarnos y capturarnos: "La mirada que Marco Aurelio dirige a las cosas (...) se refiere desde luego a sí misma, pero se refiere a sí misma de dos maneras. Por una parte, al penetrar en el corazón de las cosas, al captar todos sus elementos más singulares, se trata de mostrar hasta que punto somos libres con respecto a ellas. Pero también, y al mismo tiempo, se trata de mostrar que nuestra propia identidad - esa pequeña totalidad que constituimos a nuestros propios ojos: continuidad en el tiempo, continuidad en el espacio - no está en realidad compuesta más que de elementos singulares, elementos distintos, elementos discretos entre sí, y que es, en el fondo, una falsa unidad.” (Foucault, 2014: 297).

${ }^{14}$ Tal como señala Valdettaro, el problema de los medios digitales, no radica tanto en una exposición de la intimidad, sino en que promueven o potencian una falta de reconocimiento de la extimidad. LA autora lo demuestra a través del impacto mediático en relación a la problemática de la prohibición del velo de las mujeres musulmanas en Francia. Al respecto, comenta: "los modos de existencia levemente diferentes a los nuestros - como los de cubrirse los cabellos-, resultan, en cambio, sospechosos, y, esos sí, requieren prohibición. Se trata, en definitiva, del miedo al goce del otro lo que expresa nuestro afán de desnudarnos y de prohibir el desnudo del otro. Una cuestión en definitiva de extimidad. Eso sí circula, sin dudas, por las redes sociales" (Valdettaro, 2017: 13,14).
} 
Toda la problemática abordada hasta ahora nos muestra la tensión irreductible advertida por Mcluhan entre fondo y figura de un medio. ${ }^{15}$ Algunos autores expresan esta tensión mediante una analogía entre el contenido que circula en un medio y la leyenda escrita en el cuerpo de una bomba. El mensaje de esa leyenda es totalmente irrelevante y sólo importa el estallido que genera el dispositivo. Sólo es el medio mismo aquello que actúa como mensaje y es independiente del contenido manifiesto que se produce en su interior. Este ejemplo conduce a pensar si el uso que hacemos de la tecnología digital permite revertir el ritmo vital que la misma impone de manera performativa. En otros términos, si permite hacerse cargo de la complejidad del deseo o simplemente nos encierra en el goce que promueve las formas de vida capitalista. Para decirlo concretamente y utilizando un ejemplo bien simple, hacer un posteo en Facebook contra la maldad del capitalismo, ¿revierte todo aquello que la red social impone con su forma misma? ¿Cómo se puede lograr un efectivo cuidado de sí en la era de la tecnología digital? ¿De qué modo es posible posicionarse, relacionarse e interactuar con la misma para evitar ser fagocitados por las relaciones de dominación del capitalismo imperante?

\section{Un método materialista y una nueva mirada del dispositivo}

Lo dicho anteriormente no debe conducir a pensar que el presente escrito pretende denostar los avances de la tecnología digital ni juzgarla como causa de todos los males de la humanidad. Sólo se ha buscado mostrar un vínculo que es necesario atender entre la tecnología digital, la constitución de la subjetividad y determinados discursos sobre el ser de las cosas. He intentado hacer uso de un método materialista que apunta a percibir estas determinaciones múltiples que permiten evaluar que no hay neutralidad en los desarrollos de la técnica. En este sentido, es preciso atender a la reflexión de Althusser cuando sostiene que todo saber científico está atravesado por una ideología específica y no hay conocimiento de la realidad en sí misma como quiere la filosofía idealista. ${ }^{16}$

\footnotetext{
${ }^{15}$ Señala Mcluhan: "Me encuentro en la posición de Louis Pasteur cuando decía a los médicos que su mayor enemigo les era del todo invisible y desconocido. Nuestra respuesta convencional a todos los medios, de que lo que cuenta es cómo se utilizan, es la postura embotada del idiota tecnológico. Porque el «contenido» de un medio es como el apetitoso trozo de carne que se lleva el ladrón para distraer al perro guardián de la mente." (Macluhan, 1996: 39) Y un poco más abajo: "La imprenta creó el individualismo y el nacionalismo en el siglo XVI. Los análisis de programa y de «contenido» no ofrecen ningún indicio de la magia de estos medios ni de su carga subliminal." (Macluhan, 1996: $39)$.

16 “A diferencia de lo que creen los filósofos idealistas, la ciencia, el conocimiento no determinan la
} 
Pero, consecuentemente con este método, los argumentos críticos esbozados precedentemente, no tienen la finalidad de proponer la añoranza de una sensibilidad prístina o una vitalidad extraviada que el medio digital habría venido a pervertir, dejando atrás un paraíso perdido al cual habría que regresar.

Siguiendo esta línea, también es preciso recuperar el gesto de Latour de pensar desde la invención, para que la reflexión no se vea confundida por el presupuesto de un ideal de sociedad como un todo unificado. Tampoco por el recurso a una subjetividad definitiva en relación a la cual estos medios serían la perdición o la perversión. Más interesante resulta rastrear lo que los mismos generan, de qué modo se anudan al deseo, cuáles son los nuevos agrupamientos que forman y los puntos de fuga que dejan libres, para operar desde allí transformaciones posibles. ${ }^{17}$ Por eso, el método utilizado por el sociólogo, invita a advertir el papel que juegan estas idealizaciones para comprender y transformar la realidad. En virtud de ello, sentencia "Para decirlo sin rodeos: si existe sociedad, entonces no hay política posible" (Latour, 2008: 349). La filosofía de Badiou también resulta interesante ya que reflexiona desde la inmanencia entre la multiplicidad del ser ahí y su indexación lógica en situaciones específicas, una cuestión que permite pensar la objetividad sin presuponer entidades previas o el recurso a un sujeto fundador. ${ }^{18}$ De modo simultáneo permite ejercer una doble potencia crítica e inventiva, invitando a concebir la reflexión trascendental como

política, sino que la política determina el desarrollo de la ciencia y el conocimiento" (Althusser, 2015: 127).

${ }^{17}$ El sociólogo francés insiste en que no existe una sustancia de lo social que permita explicar aglomeraciones, sino que su método consiste en rastrear la conformación contingente y cambiante de las mismas. Desde este punto de vista, no hay grupos como una unidad necesaria, como un sustrato permanente, sino sólo formación de los mismos que se da bajo la acción de conglomerados o nodos de composición diversa que pueden ser desenmarañados. Así, no existe la Sociedad sino formas de asociación particulares y cambiantes: "la situación es enteramente diferente para la Teoría del Actor Red porque, por empezar, ni la sociedad ni lo social existen. Hay que reconocer sus huellas a través de los cambios sutiles producidos al conectar recursos no sociales. Así, cada punto de partida nos llevará a dibujar un animal completamente diferente, totalmente inconmensurable respeto de los otros. Para la primera escuela, la sociedad está siempre allí, poniendo su peso detrás de cualquier vehículo que pueda llevarla; en el segundo enfoque, los vínculos sociales tienen que ser rastreados siguiendo la circulación de distintos vehículos que no pueden sustituirse entre si"(Latour, 2008:59) Por esta razón, "No es posible decir de vínculo alguno que sea duradero ni que esté hecho de materia social" (Latour, 2008: 99).

${ }^{18}$ Señala Badiou: "el objeto es el aparecer de un ente-múltiple en un mundo determinado, y su concepto (indexación trascendental, átomos reales...) no implica ningún sujeto. (...) Ahora bien, en mi propia empresa, y bajo la condición del postulado del materialismo, la palabra "objeto" designa también el punto de conjunción, o de reversibilidad, entre lo ontológico (pertenencia a un múltiple) y la lógica (indexación trascendental), entre la invariancia de lo múltiple y la variación de su exposición mundana." (Badiou, 2006: 262). 
una función lógica y no como la realidad del ser en sí que, en última instancia, es indiscernible. Por último, el planteo foucaulteano propone cultivar una relación de sí que no se piensa por fuera de las demás relaciones de un mundo sino que emerge en la trama formada por las mismas.

Tomando en cuenta estas precisiones de método, me parecen insuficientes algunas de las principales críticas que se esgrimen hacia el medio digital en la literatura sobre el tema. Sobre todo cuando las mismas pretenden exceder la posición de diagnóstico e intentan articular una propuesta pragmática. Con todo lo que tiene de interesante el estudio de Sadin sobre las consecuencias de un tecnoliberalismo, me atrevería a sostener que su argumento muestra alguna debilidad cuando la crítica parece devenir en la añoranza de una sensibilidad cuya pureza resultaría amenazada. Según el francés, la erradicación de lo sensible, es una de las características principales del programa siliconiano: "Porque la erradicación de lo sensible representa uno de los objetivos principales del programa siliconiano, dado que cuenta encerrar la experiencia humana dentro de los dispositivos que concibe" (Sadin, 2018b: 302). Ante el avance de los medios digitales, el autor propone, como ejercicio de resistencia, una defensa de lo sensible tomando como ejemplo el deseo y la alegría que despierta un espectáculo de baile. Sería un despropósito contradecir Sadin en este punto. Es una obviedad que practicar karate (en mi caso) o ir a bailar no tiene comparación con mirar un video de alguien que practica karate o baila. Pero, de acuerdo con lo visto en el párrafo anterior, no creo que en la actualidad sea posible definir una forma de sensibilidad situada por fuera de la dinámica de los medios digitales. Y siguiendo las leyes de Mcluhan sobre la misma, creo que toda esperanza en volver a un estadio anterior a la propagación de los mismos deviene ingenua o idealista. Incluso la relación de sí deberá pensarse incluyendo lo que estos medios implican. Por otro lado, también es cierto que, si bien el medio no reemplaza la practica concreta, genera nuevas formas de contactarse con gente que también practica, compartir información, videos, etc.

Más confuso que el caso anterior, resulta el punto de vista de Byung Chul Han sobre el final del libro Piscopolítica. Después de hacer un rastreo muy interesante acerca de la omnipotencia del bigdata en su vínculo con el semiocapitalismo, en el último capítulo del libro, el pensador coreano realiza una sugerencia un tanto extraña. En efecto, parece proponer lo que llama idiotismo como una de las formas para combatir las nuevas técnicas de poder del capitalismo neoliberal. Con esta idea se refiere a la posibilidad de rastrear un espacio de pureza similar al de un niño que todavía no resulta atacado por la lógica del sistema. La inteligencia supone un movimiento dentro de las reglas de un paradigma y, por ende, no puede nunca tener un contacto con lo radicalmente 
otro. Por esta razón, Han sugiere reflexionar sobre una "pura inmanencia" que conduce a mostrar que "el vacio no se deja ni psicologizar ni subjetivizar" (Han, 2014: 126)

La posición de Han resulta curiosa ya que se jacta por momentos de superar a Foucault, pero no toma en cuenta las últimas ideas del francés en su gesto para despegarse de este nihilismo inconducente. No creo que la autonomía consista en no dejarse psicologizar o subjetivizar sino, a la manera del último Foucault, en dar un estilo propio a ese conflicto. En otros términos, asumir que estamos atravesados por la norma social, por dispositivos de poder, y que no es posible ejercer una ruptura total con los mismos. Esto implicaría la locura o la muerte. ${ }^{19}$ No obstante, es posible constituir un pliegue en los mismos, es posible detectar que cada uno de nosotros constituye una torsión singular e irreductible en la trama contingente de esos dispositivos. Por eso, aún reconociendo la calidad de su trabajo, creo que la tentativa de Han, parece una aspiración utópica y hace gala de una inocencia un poco infantil que pierde potencia a la hora de posicionarse activamente ante el presente. La solución sería limitada, ya que sugiere pensar la multiplicidad sin nombre: "El idiota se asemeja al homo tantum 'que ya no tiene ningún nombre, aunque no se le puede confundir con nadie'” (Han, 2014: 126,127) En este caso también el razonamiento se ve privado de la distinción badiouana. No hace falta recurrir a la posición del idiota para encontrar una alternativa. Basta con apreciar la dialéctica singular que se produce entre el nombre (como aparecer lógico) y aquello que remite a la multiplicidad del Ser ahí, en sí misma indiscernible.

La diferencia podría rastrearse hasta la naturaleza misma del acontecimiento. Han se ampara en la noción deleuziana del acontecimiento que, para Badiou, aún tiene restos de substancialismo al plantear el carácter homogéneo del devenir a través de la categoría de Vida. El acontecimiento en Badiou irrumpe en la estructura normalizada de un mundo de modo contingente. Es un instante fugaz y no un devenir permanente. Sobre ese instante fugaz vuelven a cerrarse las leyes del ser aunque permanezcan las consecuencias de esa nueva constitución que el acontecimiento genera: "Romper con el empirismo es pensar el acontecimiento como advenida de lo que se sustrae a toda experiencia: lo in-fundado ontológico y la discontinuidad trascendental. Romper con el dogmatismo es disjuntar el

\footnotetext{
19 "En este punto, me parece muy interesante la interpretación abierta por Farrán que vincula la hermenéutica del sujeto de Foucault con el psicoanálisis de Lacan como una forma de saber de sí: "En todo caso, lo que hay es discordancia e irreductibilidad entre los registros de la experiencia o dimensiones del ser hablante: real, simbólico e imaginario; y de lo que se trata -así como secundariamente se cura- es de saber anudar allí esas cuerdas para no volverse loco" (Farrán, 2018: $83)$.
} 
acontecimiento de todo dominio de lo Uno. Es sustraerlo a la Vida para devolvérselo a las estrellas. " (Badiou, 2008: 430). ${ }^{20}$

Así, el método esbozado brevemente en este trabajo no sólo permite develar el exceso de dominación al que nos arriesga la tecnología digital. Sino que, de modo simultáneo, pone en evidencia cierto resabio de idealismo que anida incluso en algunas posiciones críticas. Creo que es preciso deshacerse de la ilusión paranoide de que el dispositivo nos tiene atrapados por todos lados. Es erróneo reconocerle tanta potencia que llega a presuponer la capacidad omnipotente de suturar absolutamente el acontecimiento (como si eso fuera posible). Ya Foucault advirtió que allí donde hay poder hay resistencia. Aunque la misma no se presente como una ley suprema de Revolución. Siguiendo esta lógica, resulta más interesante analizar los puntos de cierre y de fuga que generan los dispositivos. Advertir que al mismo tiempo que imponen una regulación, existe un conjunto de fuerzas interpersonales, de deseos, de creencias que se ponen en juego y se articulan a partir de los mismos. No suma hacerse el idiota o proponer formas de escapismo ante los dispositivos (por más estimulantes, entretenidas y hasta necesarias que puedan resultar muchas de ellas). Más interesante es inmiscuirse en sus tramas para seguir mostrando desde allí, y del modo más estratégico posible, que existen otras formas de vida a las que podemos aspirar. Si se adopta esta mirada, no caben dudas que el problema no es el medio en sí mismo. Tal como se ha analizado, ellos pueden potenciar ciertas dinámicas de control o reforzar formas de goce que necesita el capitalismo para subsistir. Pero la clave está en el uso particular que hacemos de ellos insertos como estamos en la trama sintomática de nuestro presente. Los medios digitales no serían más que un emergente (entre tantos) de este problema más profundo.

\section{De las torsiones materialistas a un posicionamiento pragmático}

De acuerdo con lo dicho, considero posible distinguir algunos puntos en los cuáles nuestra relación con los dispositivos puede ser modificada.

El primero de ellos hace referencia al cambio onto-epistemológico sugerido en el segundo apartado. Introducir esta problemática crítica es clave para

\footnotetext{
${ }^{20}$ Y más adelante, Badiou agrega: "Por supuesto, ninguna estabilización de esta brusca ocurrencia de A en su propio campo trascendental, o bajo la jurisdicción retroactiva de su objetivación, es concebible. Las leyes del ser vuelven a cerrarse de inmediato sobre aquello que es su excepción. La autopertenencia se anula desde que es forzada, desde que ocurre. Un sitio es un término evanescente: no aparece sino para desaparecer. El problema es registrar sus consecuencias en el aparecer." (Badiou, 2008: 433).
} 
constituir una ética que pueda implicar a quienes tienen a su cargo la programación de algoritmos. ${ }^{21}$ Sería prudente que en los trayectos formativos de esas profesiones se pueda instalar el debate acerca del carácter ideológico de las producciones técnicas. Es preciso enriquecer la formación de técnicos e ingenieros con un abordaje epistemológico materialista -crítico del positivismo ingenuo- acerca de las teorías de la información. También es prudente organizar una sólida formación en medios digitales desde las instancias medias de la educación. Ahora que su presencia se ha naturalizado, no se trata de negarla, sino de poner de manifiesto su vínculo con la política, la economía, la sexualidad, etc. ${ }^{22}$ Es obvio que la producción científica también se ve limitada cuando queda subsumida a las imposiciones de una lógica de mercado. Así, la cuestión no pasa por un rechazo oscurantista de la ciencia y la tecnología. Por el contrario, considero que la ciencia informática sí permite formas de fidelidad al acontecimiento e incluso puede favorecer la constitución de una relación de sí. Pero habría que dilucidar bien bajo qué condiciones puede hacerlo. Siguiendo a Badiou, creo que la clave está en detectar que un conjunto de ideas científicas puede ser meramente reaccionarias y articularse en base a los principios arcaicos e inhumanos que ostenta la ideología neoliberal en su alianza con el sistema financiero. La constitución subjetiva sería arrastrada en este movimiento hacia un nuevo fetichismo que tiene como punto de anclaje la tecnología digital. En Manifiesto por la filosofía Badiou rescata la potencia infinita de la técnica siempre que no esté sometida a la lógica que impone el reinado del capital: "Sí, hay que decir: '¡Señores técnicos, todavía otro esfuerzo si realmente quieren el reino planetario de la técnica!'. Una escasez técnica aún muy zafia, tal es la verdadera situación: el reinado del capital frena y simplifica la técnica, cuyas virtualidades son infinitas." (Badiou, 2007: 32). Siguiendo esta lógica, también se hace necesario el diseño de políticas estatales que tomen a su cargo la creación de marcos normativos regulatorios. Tanto para el uso de medios digitales como

\footnotetext{
${ }^{21}$ Este punto también es reconocido por Sadin cuando sostiene que los científicos deben tomar consciencia de estos nudos de relaciones entre la política y la ciencia. En relación al desarrollo de una ética para ingenieros, el autor afirma: "Le toca a cada ingeniero decidir ser un actor que busque, de buena fe, participar en la mejora de la vida de las personas y no conformarse con ser un simple ejecutante que no se preocupa sino por ejercer sus aptitudes y cobrar ganancias, remitiéndose, en lo que hace a los desafíos o elogans acuñados por otras personas" (Sadin, 2018b: 296).

${ }^{22}$ En este punto sigo el estudio de José Van Dijck cuando afirma: "Precisamente ahora que ya contamos con una generación que percibe los medios sociales ni más ni menos que como algo dado una infraestructura que no cuestionan- resulta de fundamental importancia explicitar las estructuras ideológicas que subyacen a los microsistemas y a su ecología. Muchos de los mecanismos y economías analizados en los capítulos precedentes merecen estudiarse con mayor profundidad."(Van Dijck, 2016:178).
} 
para incrementar la información sobre los mismos. También es urgente promover la producción de ciencia y tecnología por fuera de los sectores concentrados de poder económico. En este sentido, el giro neoliberal que sufre la Argentina desde el año 2015, sienta un precedente triste para una institución como el Conicet destinada a la investigación libre de las diferentes ramas del conocimiento científico. La desregulación del mercado ha vuelto a ajustar los engranajes de una economía de endeudamiento. El flujo de capital hacia los organismos internacionales de crédito vuelve a generar estragos sobre amplios sectores de la sociedad. Una de las consecuencias más alarmantes de esta política mortífera es la creciente desinversión en ciencia y tecnología.

Por otro lado, el método permitiría posicionarse de otro modo ante la dinámica constitutiva del dispositivo. Más que paralizarse ante su aparente omnipotencia, se trata de pensar a partir de ellos, de anudar entre sus tramas, de reconocer de qué modo se pueden articular luchas colectivas y contraatacar a su impronta invasiva. En este punto, es menester realizar algunas distinciones. Por supuesto que no se puede sustituir el valor de la militancia, del encuentro concreto con otros, de la organización partidaria, sindical y quedarse sentado detrás de la pantalla. Pero incluso la famosa actitud reaccionaria del "no te metas", que recomienda no implicarse en posiciones militantes por temor a las consecuencias, es mucho más antigua que la difusión y la hegemonía de la tecnología digital. Por esta razón, hay usos de los medios digitales que pueden potenciar ciertos contactos, generar articulaciones de deseos, creencias, convicciones y, hoy por hoy, es menester tenerlos en cuenta. Claramente esta es una vía para seguir pensando en un conjunto de investigaciones que podrían multiplicarse. Pero lo dicho debe servir como prueba de que todo dispositivo es contingente $\mathrm{y}$, al mismo tiempo que sujeta, puede utilizarse para producir desestabilizaciones. En este punto, es interesante la opinión de Groys cuando contrapone la acción neutral del sujeto del administrador (Google, Facebook, etc.) con la acción de Wikileaks como sujeto de una conspiración universal. ${ }^{23} \mathrm{La}$ idea de Assange es utilizar la potencia de "cierta inteligencia matemática (...) para dotar a todos los individuos de la capacidad de decir 'no' al Estado más peligroso" (Assange, citado en Groys, 2016: 191). La acción de este ciberactivista permite mostrar que, aún siguiendo la dinámica de la inteligencia matemática, se pueden desestabilizar relaciones de dominación:

\footnotetext{
${ }^{23}$ Mientras termino de escribir este trabajo, Assange es entregado por el gobierno ecuatoriano a la policía británica y EE UU pide su extradición: (https://www.pagina12.com.ar/186784-assange-a-tirode-extradicion)
} 
Ellos se volvieron disidentes del servicio universal y, por lo tanto, inventaron una nueva forma de riesgo. $\mathrm{O}$, mejor aún, tematizaron este riesgo y lo hicieron explicito al comprometerse con el servicio y la administración universales como forma de conspiración. Esta es una verdadera innovación histórica y se espera que tenga interesantes consecuencias (Gorys, 2016: 193).

También resulta interesante la apreciación de Van Dijck cuando se refiere a la gran diversidad cultural y un conjunto de iniciativas por fuera de las plataformas hegemónicas, llevadas a cabo por jóvenes entusiastas que promueven una socialización online diversificada y equilibrada: "Junto con los pocos peces gordos que dominan el ecosistema -y que ocuparon el centro de atención en este libro- existen muchas plataformas más pequeñas, especializadas, comerciales y sin fines de lucro, que parecen invisibles para el gran público." (Van Dijck, 2016: 178).

Por último, es preciso detenerse en la articulación entre los medios digitales y el problema de la constitución de sí. Es sabido que el sujeto no remite a una substancia definitiva sino a una relación compleja en la que intervienen múltiples factores. Desde este punto de vista, esta caracterizado por la alternancia inmanente entre lo activo y pasivo, entre la libertad y la determinación. Como sugerimos más arriba, es constituido por un conjunto de reglas sociales que no puede manejar a su antojo pero, en cuya trama, puede introducir algo de su singularidad como punto de inversión respecto a esas imposiciones. ${ }^{24}$ Así, el sujeto es al mismo tiempo el punto en el que se cristalizan las relaciones de dominación y el sitio desde el cual pueden revertirse las mismas. El asunto pasa por experimentar esta dinámica y trabajar en desarrollar las potencias infinitas e inmanentes de la invención. Por esta razón, toda la tarea crítica de desnaturalización de supuestos ontológicos, encuentra en el trabajo sobre sí su punto más importante.

Aún así, la cuestión está en saber cómo hacer para que ese trabajo no caiga en el mero cliché, es decir, que no se reduzca a la repetición acrítica de las formas de vida dominante. En esta línea, me parece interesante el vínculo que propone Farrán entre el uso del Facebook y ciertas formas de escritura de sí capaces de generar la implicación del sujeto con determinadas verdades y prácticas. Según el autor, puede hacerse un uso de este medio que no se reduzca a la mera

\footnotetext{
${ }^{24}$ Como señala Farrán: "La verdad, no se da sólo como determinación negativa, o solución de compromiso, sino como sobredeterminación compleja en la cual el sujeto en tanto agente se implica en el proceso genérico objetivo que lo constituye como paciente de un acto que lo excede infinitamente. El anudamiento del sujeto se hace porque se es y se es porque se hace." (Farrán, 2018: 93).
} 
mostración narcisista ni a generar una zona de confort excluyente de la relación con el otro. Siguiendo la deriva del último Foucault, la clave estaría en poder utilizar lo que se llama "muro" a la manera de los antiguos hypomnemata de la tradición estoica. ${ }^{25}$ Esto supone una intervención desde el interior mismo del dispositivo para mostrar un uso disidente que, al mismo tiempo, puede comprometer, implicar y constituir al sujeto. Es decir, puede servir como una herramienta más en el arduo trabajo de constitución de sí:

Lo que hay que poner a prueba a través del uso singular Facebook, es si se puede escribir de manera tal que no se trate simplemente de expresarse o hacer catarsis sino de trabajar el sí mismo a través de fragmentos de escritura que al exponerlos, reunirlos, compartirlos con algunos otros, impliquen la producción de un estilo y una estética de la existencia. (Farrán, 2018: 60).

De acuerdo con todo lo dicho, desde la relación de sí se pueden generar movimientos en la tensión señalada por Mcluhan entre forma y contenido del medio. El medio no es algo neutral y externo al sujeto - entendido como una substancia individual- en el cual este último participa y vuelca un contenido que no podría revertir la forma. Por el contrario, a la manera de una cinta de moebio, se anudan la forma y el contenido en un proceso de mutua implicancia y cambio, de determinaciones recíprocas y simultáneas. La relación de sí, es la condición inmanente de todo este proceso $\mathrm{y}$, por ende, es el punto en el cual pueden generarse inversiones mediáticas (y las inversiones en los dispositivos de dominación). Así lo sugiere Harman Graham cuando afirma: "Mas que pensar que los humanos somos el contenido de cualquier medio, podríamos pensar que somos el medio de cualquier contenido que sea más que un cliché". (Graham, 2015: 263) Aún así, no sería prudente concebir este medio -el "yo"- como parece hacerlo el autor, es decir, desde la óptica kantiana de una unidad trascendental de la apercepción. Por el contrario -y nuevamente tratando de no contraer deudas con la filosofía idealista- el trabajo sobre sí se relaciona con el rastreo de un sitio inmanente respecto a las demás relaciones del mundo y sin postular una unidad esencial como fundamento invariable de su contenido.

\footnotetext{
${ }^{25}$ En este sentido, señala Farrán: "Mi hipótesis es que Facebook, puntualmente escribir en lo que se llama "muro" anécdotas, citas, aforismos, reflexiones, etc., en fin, reunir escritos fragmentarios de diversa índole y procedencia para su posterior relectura, meditación, y recolección en otros escritos más sistemáticos, puede resultar por ende algo distinto a una mera mostración narcisista de imágenes de un yo plenamente constituido que no se problematiza a sí mismo(imágenes habitualmente ligadas al consumo); puede ser, al contrario, un modo de constituirse como sujeto de un discurso verdadero, una práctica de escritura que se coloca en un registro intermedio (interfaz) entre lo público y lo privado; tal era el caso de los antiguos Hypomnémata" (Farrán, 2018: 57-56).
} 


\section{Conclusión}

Para concluir, considero que la reflexión desarrollada en el presente escrito conduce a distinguir diferentes tramas: En primer lugar, advierte el lazo entre la ontología, la lógica algorítmica y su vínculo con las relaciones de poder imperantes; en segundo lugar, apunta a repensar la dinámica constitutiva respecto a la subjetividad y a la vida social- de los dispositivos digitales; por último, invita a reconocer el trabajo de sí como punto nodal en el cual se pueden operar transformaciones respecto a los mismos. Considero que el análisis del modo en que se articulan estas tramas permite develar el uso de los dispositivos en su exceso totalitario. En efecto, hace posible advertir las situaciones en las cuales, los medios digitales, quedan anudados a una voluntad de verdad sumamente dominante que desconoce su historicidad, su contingencia y su carácter ideológico. A su vez, como el método piensa en términos de inmanencia e invención, y no presupone ideas externas acerca de la naturaleza del sujeto y la sociedad, habilita otra mirada acerca del carácter productivo de estos dispositivos. Es precisamente a partir del juego incesante de sus aperturas y cierres, que se visualizan diferentes sitios en los cuáles los medios pueden ser efectivamente transformados. En el mismo movimiento, surge un modo de pensar nuestra propia constitución subjetiva que apunta a ser capaces de anudar conjuntamente con otros (personas, medios, disposiciones culturales, etc.), del modo más reflexivo posible y evitando diferentes excesos. No existen soluciones mágicas. No obstante, la línea de trabajo expuesta, se presenta como un hilo de Ariadna para orientar un uso de los medios digitales que contribuya a pertrecharse y luchar ante los abusos generados por el capitalismo neoliberal.

\section{Bibliografía}

Althusser, L (2015) Iniciación a la filosofia para los no filósofos. Buenos Aires: Paidós.

Badiou, A. (2008) Lógica de los mundos: El ser y el acontecimiento 2. Buenos Aires: Manantial.

(2002) Breve tratado de ontología transitoria. Barcelona: Gedisa Editorial.

(2007) Manifiesto por la filosofia. Buenos Aires: Nueva Visión.

Byung Chul Han. (2014) Psicopolítica. Buenos Aires: Herder.

Farrán, R. (2018) El uso de los saberes. Filosofía, Psicoanálisis y Política. Córdoba, Argentina: Borde Perdido Editora. 
Foucault, M. (2014) La hermenéutica del sujeto. Buenos Aires: Fondo de Cultura Económica.

(2016) El origen de la hermenéutica de sí. Conferencias de Darthmouth, 1980. Buenos Aires: Siglo XXI.

Groys, B. (2016). Arte en flujo. Ensayos sobre la evanescencia del presente. Buenos Aires: Caja Negra.

Latour, B. (2008). Reensamblar lo social. Una introducción a la teoría del Actor-Red. Buenos Aires: Manatial.

Latour, B; Lepinay (2007) La economía: Ciencia de los intereses apasionados. París: Los aguafiestas:

Mcluhan, M. (1996) Comprender los medios de comunicación. Las extensiones del Ser Humano. Barcelona: Paidós.

Mcluhan, M; Mcluhan, E. (2009) "Las leyes de los medios" Cuadernos de Información y comunicación, vol 14, pp. 285-316. Madrid: Universidad Complutense de Madrid.

Rodríguez, P. (2012). Historia de la información. Del nacimiento de la estadística y la matemática moderna a los medios masivos y las comunidades virtuales. Buenos Aires: Capital Intelectual.

Sadin, E. (2018). La humanidad aumentada. La administración digital del mundo. Buenos Aires: Caja Negra.

(2018 b). La silicolonización del Mundo. La irresistible expansión del capitalismo digital. Buenos Aires: Caja Negra.

Srnicek, N. (2018) Capitalismo de plataformas. Buenos Aires: Caja Negra.

Valdettaro Sandra (2017) "Mediatización y segregación: anotaciones sobre la extimidad", en Busso M. y Camusso M. Editoras, Mediatizaciones en tensión: el atravesamiento de lo público, Rosario: UNR Editora. En www.cim.unr.edu.ar Van Dijck, J. (2016) La cultura de la conectividad. Una historia crítica de las Redes sociales. Buenos Aires: Siglo XXI

Zaffaroni, E.; Dos Santos, I. (2019) La nueva crítica criminológica. Criminología en tiempos de totalitarismo financiero. Quito-Ecuador: Editorial El Siglo 